\title{
Reflectance spectroscopy of indoor settled dust in Tel Aviv, Israel: comparison between the spring and the summer seasons
}

\author{
A. A. Chudnovsky ${ }^{1}$, E. Ben-Dor ${ }^{1}$, and H. Saaroni ${ }^{2}$ \\ ${ }^{1}$ Remote Sensing and GIS Laboratory, Department of Geography and the Human Environment, Tel-Aviv University, Israel \\ ${ }^{2}$ Unit for Applied Climatology and Environmental Aspects, Department of Geography and the Human Environment, Tel-Aviv \\ University, Israel
}

Received: 16 February 2007 - Revised: 27 May 2007 - Accepted: 26 June 2007 - Published: 4 July 2007

\begin{abstract}
The influence of mineral and anthropogenic dust components on the VIS-NIR-SWIR spectral reflectance of artificial laboratory dust mixtures was evaluated and used in combination with Partial Least Squares (PLS) regression to construct a model that correlates the dust content with its reflectance. Small amounts of dust $\left(0.018-0.33 \mathrm{mg} / \mathrm{cm}^{2}\right)$ were collected using glass traps placed in different indoor environments in Tel Aviv, Israel during the spring and summer of 2005. The constructed model was applied to reflectance spectroscopy measurements derived from the field dust samples to assess their mineral content. Additionally, field samples were examined using Principal Component Analysis (PCA) to identify the most representative spectral pattern for each season. Across the visible range of spectra two main spectral shapes were observed, convex and concave, though spectra exhibiting hybrid shapes were also seen. Spectra derived from spring season dust samples were characterized mostly by a convex shape, which indicates a high mineral content. In contrast, the spectra generated from summer samples were characterized generally by a concave shape, which indicates a high organic matter content. In addition to this seasonal variation in spectral patterns, spectral differences were observed associated with the dwelling position in the city. Samples collected in the city center showed higher organic content, whereas samples taken from locations at the city margins, near the sea and next to open areas, exhibited higher mineral content. We conclude that mineral components originating in the outdoor environment influence indoor dust loads, even when considering relatively small amounts of indoor settled dust. The sensitive spectral-based method developed here has potentially many applications for environmental researchers and policy makers concerned with dust pollution.
\end{abstract}

Correspondence to: A. A. Chudnovsky

(chudnovs@post.tau.ac.il)

\section{Introduction}

To date, when considering health problems related to dust exposure, the focus has been on dust inhalation, due to dust suspended in the air, whereas contact with settled (or sediment) dust has been largely ignored. However, exposure to certain types of settled dust and its associated contaminant load can be detrimental to human health, and has been associated with various pathologies, including systemic poisoning, hard metal disease, several irritations, nasal obstruction, eye problems, infections, and dermatological aberrations (Maertens et al., 2004). Children, who tend to play or crawl on the floor and place objects in their mouths that have been in intimate contact with dusty floors, are particularly at risk from such health complications. In certain environments, airborne particles and settled dust are especially undesirable, as they constitute contaminants that interfere with the activities conducted in these environments (Morawska and Salthammer, 2004). For example, in medical facilities a lack of cleanliness can endanger the lives of patients, and in facilities where electronic equipment is manufactured the presence of any form of dust contamination disturbs significantly the product quality. More generally, the composition of indoor settled dust, in addition to reflecting the degradation of indoor materials, is a key indicator of air pollution (Vallack and Shillito 1998; Shneider, 2004). Thus, in order to regulate effectively polluting emissions, policy makers need accurate information regarding indoor settled dust and specifically how its composition reflects the outdoor environment.

Outdoor particles infiltrate into the indoor environment and have been shown to contribute significantly to indoor dust loads (Riley et al., 2002). In the outdoor environment natural sources of dust particles include sand, clay, soil, organic materials, pollen, forest fire emissions and volcanic debris. Anthropogenic sources of dust include fossil fuel combustion (e.g., coal, oil), wood combustion, waste incineration and a variety of industrial processes (e.g., iron

Published by Copernicus Publications on behalf of the European Geosciences Union. 
founding, construction). In the indoor environment, in addition to the particles from natural and anthropogenic outside sources, there are particles from skin, hair, mites, clothing fibers and furnishings, cooking emissions, bacteria, smoke residuals, cleaning products, organic acids, building materials, and from a multitude of other materials present or utilized indoors (Roberts et al., 1992). The myriad indoor and outdoor sources of settled indoor dust result in a complex mixture, which is extremely heterogeneous, varying from place to place and across time. This heterogeneity is reflected by the diverse sizes, shapes, composition, chemistry and concentration of indoor dust particles. Accordingly, the composition of settled house dust can differ not only among geographic locations, but even between rooms of a single house (Lioy et al., 2002; Morawska and Salthammer, 2004).

Summarily, the level and composition of indoor settled dust is affected by outdoor environment characteristics, indoor activity, and life patterns. Discerning accurately what influences the composition of indoor settled dust has become an urgent goal for both environmental researchers and policy makers. A large variety of field techniques for assessing settled dust have been described in the literature. Recently, Chudnovsky et al. (2007) developed a new spectral-based method for assessing quantitatively and accurately small amounts of dust (from $0.018-0.45 \mathrm{mg} / \mathrm{cm}^{2}$ ). For any given sample, its Visible-Near Infrared-Short Wave Infrared (VISNIR-SWIR) spectrum (400-2400 nm) contains invaluable diagnostic information concerning both organic and inorganic constituents, making reflectance spectroscopy a promising tool for environmental research. Nevertheless, before the work of Chudnovsky et al. (2007) very few studies had used reflectance spectroscopy for assessing settled dust and those few dealt only with large amounts of settled dust to ensure measurement of strong spectral responses (Ong et al., 2003; Arimoto et al., 2002, and a research study conducted by the United States Geological Survey in collaboration with NASA, http:/greenwood.cr.usgs.gov). Chudnovsky's method combines reflectance measurements with multivariate regression analysis. When the method was applied to analyze indoor dust samples collected during the spring, it was found that samples could be categorized into two types according to their spectral shape: (type A) a convex slope across the VIS due to significant mineral content, which was mostly representative of dwellings, and (type B) a concave slope across the VIS due to dominant anthropogenic/organic content, mostly representative of office environments (Chudnovsky and Ben Dor, 2007). In this study, the new spectralbased method is used to evaluate in detail the influence of outdoor environmental conditions on indoor settled dust collected from dwellings in Tel-Aviv, Israel.

Other studies have addressed more generally the environmental impact of dust storms on daily life. The negative consequences of dust deposition include urban air pollution, biodiversity reduction, as well as sand encroachment on productive land, human settlements and infrastructure. It is es- timated that between 30 and $50 \%$ of indoor floor dust is derived from soils (Fergusson and Kim, 1991). Here, in order to gain a more quantitative understanding of how dust storms affect indoor dust, we compare the spectral behavior of indoor settled dust collected during two seasons, the spring (which are associated with dust storms) and the summer.

\section{Method}

\subsection{Dust traps and spectral measurements}

We have found that the optimal configuration for a dust trap is a glass disk ( $2 \mathrm{~mm}$ thick) with a black carbon background placed underneath. This configuration maximizes the capacity to detect meaningful spectral characteristics due to the dust mixture resting on the glass. Spectral measurements were recorded for each glass trap before and after dust exposure to enable precise identification of dust-related spectral changes. Dust samples were scanned by the Analytical Spectral Devices FieldSpec Pro (ASD 2001) spectrometer, which has a large spectral range $(350-2500 \mathrm{~nm})$. The contact probe ("potato") device was attached to the dust sample. The "potato" was set on a stable tripod base and maintained in a constant position at a nadir-looking angle. $\mathrm{BaSO}_{4}$ powder in the same geometry was used as a white reference to enable conversion of the measurement data into reflectance values. In addition, the gravimetric weight of each dust trap was measured using a sensitive analytical scale (Mettler AE163), with a precision of $0.01 \mathrm{mg}$.

\subsection{Location of dust traps}

Two field experiments of one month length were conducted, the first during the spring (April 2005) and the second during the summer (August 2005). The dust traps were placed in similar locations during the spring and the summer seasons, but in the summer experiment more dwellings were under study. Forty-five residential dwellings from the northern and central parts of Tel Aviv were sampled during April 2005, and one hundred and thirty-five residential dwellings were sampled during August 2005. The traps (2-4 in each dwelling) were placed on flat surfaces (tables, shelves, and boxes) at a height of $1.3 \mathrm{~m}$ above the floor, at least $0.5 \mathrm{~m}$ away from large electrical appliances, and positioned so that the column of air above the sampling surface was unobstructed (Edwards et al., 1998). Additionally, several traps were placed outdoors.

\subsection{Study period}

During the summer months in Israel the lower atmospheric levels are dominated by a synoptic system known as the "Persian Trough", which is associated with persistent northwesterly, Etesian winds (Alpert et al., 1990; Saaroni and Ziv, 2000; Ziv et al., 2004). Figure 1a presents the average 
sea level pressure (SLP) map for August 2005, indicating a Persian Trough with a northwesterly flow. In contrast, the spring season is characterized by transient systems including the "Sharav" cyclones that move eastward along the North African coast and are responsible for severe dust events over the Eastern Mediterranean (Alpert and Ziv, 1989). During April 2005 five dust storms swept across Israel mostly as a result of "Sharav" cyclones (30-31 March, 6-7 April, 11-12 April, 17-18 April, and 22 April). An average of 9.3 dusty days was recorded during the sampling period of April 2005. Figure $1 \mathrm{~b}$ presents the average SLP map for 7 April 2005, showing a "Sharav" cyclone located over western Egypt and a warm sector of the cyclone over Israel, which resulted in south-easterly winds that transported the dust to Israel.

\subsection{Laboratory spectral assessment of the dust source}

In order to create reference dust samples that reveal the spectral influence of anthropogenically generated materials on natural substances, we constructed artificial mixtures of dust and soot. We added known amounts of soot to a certain amount of dust (collected after a dust storm), to produce mixtures with 25,50 , and $75 \%$ soot content. Very small amounts of each mixture were spread homogeneously and gently above a glass trap. Before and after the dust was spread, these four glass traps were weighed and spectral measurements taken (see Sect. 2.5).

\subsection{Data analyses}

For spectral analyses of small amounts of dust, we used the Difference Index (DI) (Chudnovsky et al., 2007). Difference Index $(D I)$ spectra were calculated for each waveband, as follows:

$D I_{(\lambda)}=B_{\text {rad }(\lambda)}-B_{\text {background }(\lambda)}$,

where $B_{\operatorname{rad}(\lambda)}$ is the reflectance of the dust plus the reflectance of the glass disk, plus the reflectance of the black carbon background and where $B_{\text {background }(\lambda)}$ is the reflectance of the clean glass disk plus that of the black carbon background.

To analyze and compare the spectra of samples collected during the two seasons, we employed two methods: Partial Least Squares (PLS) regression and Principal Component Analysis (PCA). All data management, calculations, PLS and PCA analyses were performed using Unscrambler software, Version 9.1 (Camo, Norway 2004).

PLS Regression: A PLS model was calculated using the laboratory mixtures with total mineral content $(100,75,50$, 25, and $0 \%$ ) and correlated with VIS-NIR-SWIR spectra:

$Y n=A+A_{1} D I_{1}+A_{2} D I_{2}+A_{3} D I_{3} \ldots+A_{n} D I_{n}$,

where $Y n$ is the mineral content of the artificial dust sample, $A_{i}$ are empirical coefficients, and $D I_{i}$ is the $D I$ spectral reflectance at a specific wavelength. Statistical parameters for
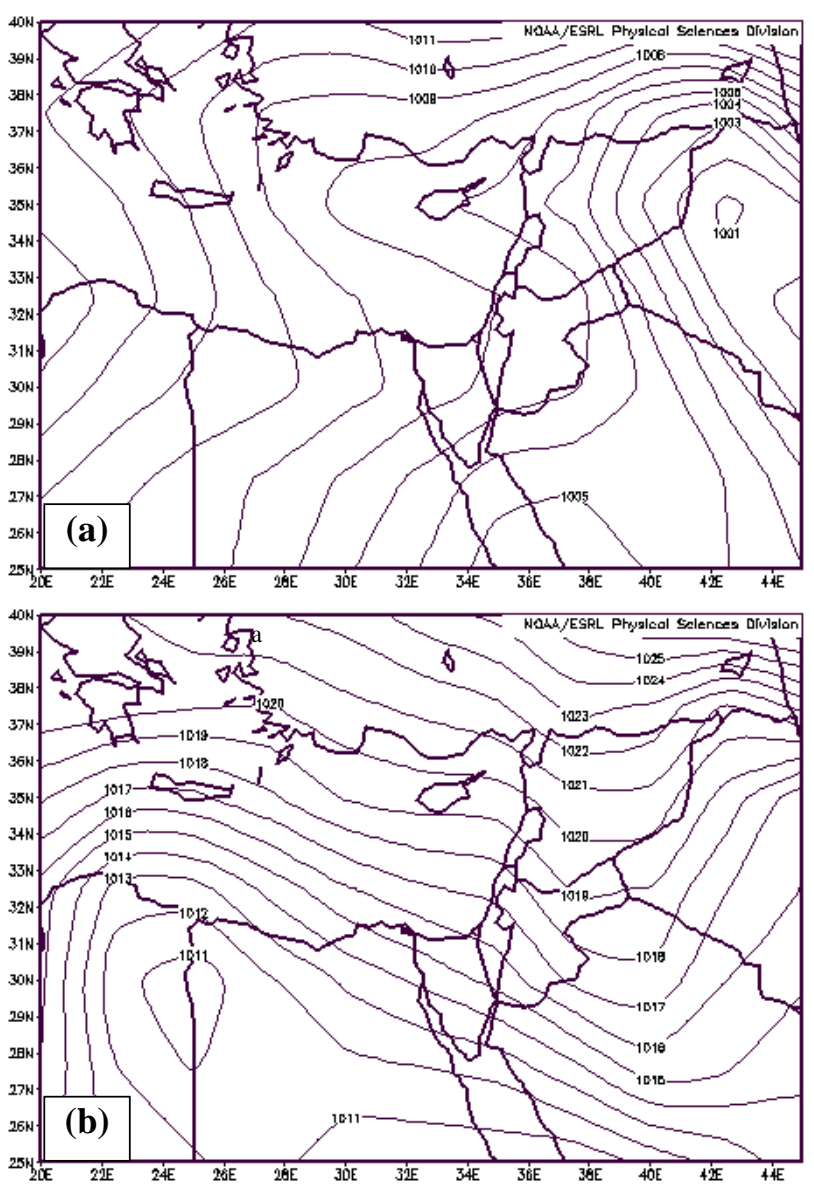

Fig. 1. Sea level pressure (a) averaged over August 2005 and (b) for 7 April 2005, based on the NCEP-NCAR CDAS-1 archive (Kalnay et al., 1996; Kistler et al., 2001).

the model were calculated by leave-one-out-cross-validation (only one sample at a time is kept out of the calibration and used for prediction) (Adams, 1995). The constructed model was run on the two field data sets (spring and summer sets) to assess the presence or absence of mineral content among different indoor dust samples. For each data set, the "center of gravity" (CG, or the mean center of both the $\mathrm{X}$ - and $\mathrm{Y}$ axes) of a predicted values distribution was calculated (Lloyd and Dicken, 1972).

Principal Component Analyses (PCA): DI spectra of samples from both field data sets were examined by PCA to differentiate the dust composition between the seasons. PCA transforms the original independent variables (wavelengths) into new axes, or principal components (PCs). These PCs are orthogonal, so that the datasets presented on these axes are uncorrelated with each other (Esbensen, 2002). The spectral patterns derived using PCA provide information about the characteristic peaks, indicating which are the most significant ones when discriminating dust samples according to season. 
Table 1. Basic statistical parameters describing the amounts of settled indoor and outdoor dust collected during the spring and summer seasons.

\begin{tabular}{lcccccccc}
\hline \multirow{2}{*}{ Experimental } & \multicolumn{4}{c}{ Indoor Environment } & \multicolumn{3}{c}{ Outdoor Environment } \\
\cline { 2 - 9 } & $\begin{array}{c}\text { Mean } \\
\left(\mathrm{mg} / \mathrm{cm}^{2}\right)\end{array}$ & $\begin{array}{c}\text { Max } \\
\left(\mathrm{mg} / \mathrm{cm}^{2}\right)\end{array}$ & $\begin{array}{c}\text { Min } \\
\left(\mathrm{mg} / \mathrm{cm}^{2}\right)\end{array}$ & $\begin{array}{c}\text { Stdev } \\
\left(\mathrm{mg} / \mathrm{cm}^{2}\right)\end{array}$ & $\begin{array}{c}\text { Mean } \\
\left(\mathrm{mg} / \mathrm{cm}^{2}\right)\end{array}$ & $\begin{array}{c}\text { Max } \\
\left(\mathrm{mg} / \mathrm{cm}^{2}\right)\end{array}$ & $\begin{array}{c}\text { Min } \\
\left(\mathrm{mg} / \mathrm{cm}^{2}\right)\end{array}$ & $\begin{array}{c}\text { Stdev } \\
\left(\mathrm{mg} / \mathrm{cm}^{2}\right)\end{array}$ \\
\hline Spring & 0.12 & 0.33 & 0.02 & 0.08 & 1.31 & 1.86 & 0.74 & 1.0 \\
\hline Total & 0.09 & 0.25 & 0.01 & 0.06 & 1.08 & 0.65 & 0.37 & 0.04 \\
\hline Summer & \multicolumn{9}{c}{90 traps } & & \multicolumn{3}{c}{15 traps } \\
\hline Total
\end{tabular}

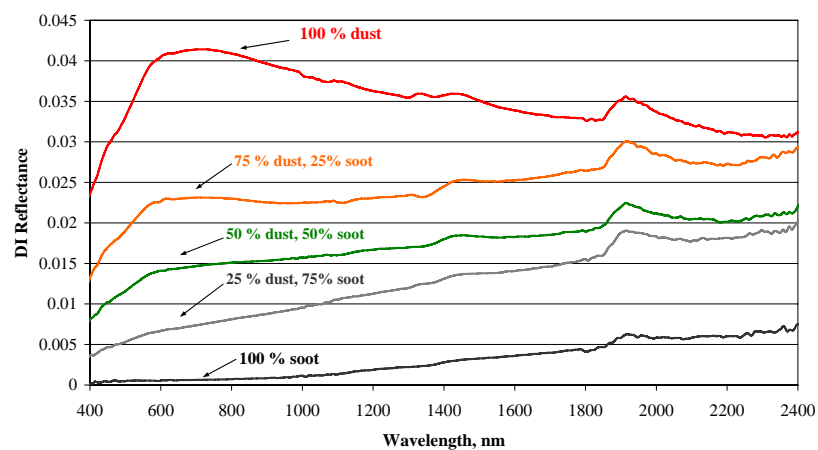

Fig. 2. Difference reflectance spectra $(D I)$ of constructed artificial mixtures of dust and soot: 1) $100 \%$ dust, 2) $75 \%$ dust and $25 \%$ coal, 3) $50 \%$ dust and $50 \%$ coal, 4) $25 \%$ dust and $75 \%$ coal, and 5) pure coal.

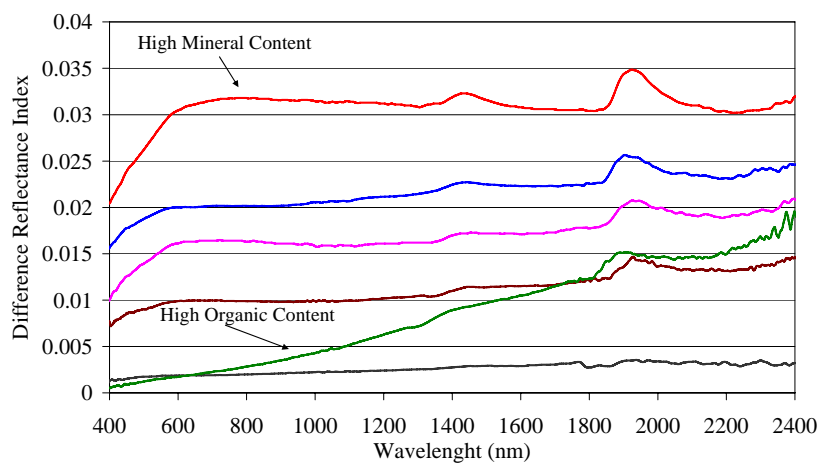

Fig. 3. Representative $D I$ spectra of dust samples collected in various indoor environments. (a) denotes a spectrum that indicates high mineral content, (b) denotes a spectrum that indicates high organic content.

\section{Results}

During the spring, the gravimetric weight of an indoor dust sample (90 samples) ranged from $0.02 \mathrm{mg} \mathrm{cm}^{-2}$ to $0.33 \mathrm{mg} \mathrm{cm}^{-2}$, with an average of $0.12 \mathrm{mg} \mathrm{cm}^{-2}$ (Table 1).
During the summer, the gravimetric weight of an indoor dust sample (135 samples) was generally lower, ranging from $0.01 \mathrm{mg} \mathrm{cm}^{-2}$ to $0.25 \mathrm{mg} \mathrm{cm}^{-2}$, with an average of $0.09 \mathrm{mg} \mathrm{cm}^{-2}$. This seasonal difference in indoor dust load is likely explained by the observed large seasonal disparity in outdoor dust loads resulting from the spring dust storm events. The outdoor dust samples ranged from 0.74 to $1.86 \mathrm{mg} \mathrm{cm}^{-2}$ during the spring and from 0.37 to $0.65 \mathrm{mg} \mathrm{cm}^{-2}$ during the summer (Table 1). These observations corroborate the general tenet that outdoor dust has a significant effect on the indoor dust environment. Alternative parameters that might be influencing indoor dust deposition loads include anthropogenic activity and crowding. However, the discrepant environmental conditions in the various dwellings (open and closed windows, different indoor activities, etc.) mean it is impossible to conclude unequivocally how these other parameters contribute to quantitative differences in gravimetric weight among samples.

Laboratory and field dust samples: Figure 2 presents the DI spectra of different kinds of artificial dust mixtures that were spread above glass traps under controlled laboratory conditions (the total dust loads varied from 1.5 to $2.5 \mathrm{mg}$ ). The presence of iron oxides results in elevated reflectance in the red portion of the spectrum (500-700 nm, VIS) and therefore contributes to a convex shape for the slope appearing in the VIS-NIR spectral region, termed a strong absorption edge. Notably, increasing the soot content of a dust sample converts this slope from a convex to a concave shape between 500 and $1400 \mathrm{~nm}$. Figure 3 shows the spectra of several representative indoor dust samples from both seasons. In the spectral region from $400-1000 \mathrm{~nm}$, each spectrum exhibits a distinct slope, ranging from convex to concave and including various hybrids of these shapes. These spectral data indicate that there are varying amounts of mineral and organic contents in the samples, which is supported by the divergent colors of the indoor dust samples observed during both seasons. However in general, gray dust samples were observed mostly during summer (indicating a higher organic content), whereas a shade of red-yellow was prevalent among dust samples during spring (reflecting a higher mineral content). 


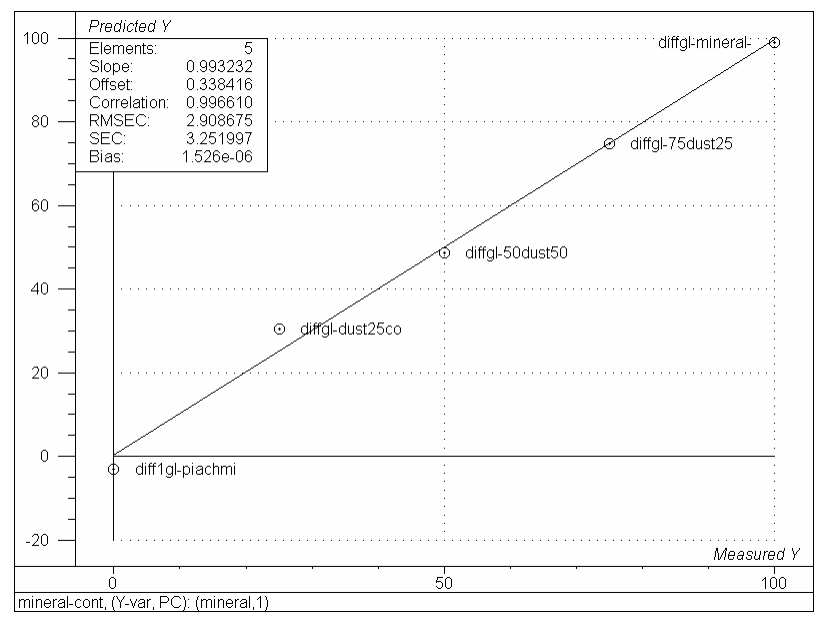

Fig. 4. PLS modeling of mineral content based on artificial laboratory dust mixtures: 1) diffgl-mineral corresponds to $100 \%$ mineral dust, 2) diffgl-75dust-25coal corresponds to $75 \%$ dust and $25 \%$ coal, 3) diffgl-50dust 50 relates to $50 \%$ dust and $50 \%$ coal, 4) diffgldust 25 corresponds to $25 \%$ dust and $75 \%$ coal, and 5) diff $1 g l$ piachmi to pure coal (negative value).

PLS modeling and prediction of mineral content: Figure 4 shows PLS modeling of mineral content based on artificial laboratory dust mixtures. The model provides good precision $\left(R^{2}=0.98\right.$ or $\left.r=0.99\right)$ and accuracy (RMSEP $\left.=2.5 \%\right)$, with a slope of 0.96. This model was run on the field data sets; Figs. $5 \mathrm{a}$ and $\mathrm{b}$ present the predicted mineral contents for the spring and summer samples, respectively. For the spring data set, a prediction could be made for 80 out of the 90 samples; the model gave negative values for the "unpredictable" 10 samples, perhaps indicating the absence of mineral content (not shown in Fig. 5a). The model enabled predictions for 87 out of 135 summer dust samples, and for the remaining 48 samples negative values were received (Fig. 5b, data not shown). The calculated CG values support that the spring samples have higher mineral content (with a mean predicted mineral content of 28.6\%), whereas the summer samples exhibit lower mineral content (with a mean predicted mineral content of $16.8 \%$; Table 2). Of note, among the summer data set a convex spectral behavior dominates in samples that were located adjacent to the seashore, open areas, and near areas under construction. In contrast, samples located in the city center are characterized by distinctive concave spectral slopes indicative of high soot content.

PCA Analyses: Figure 6 shows the first Principal Component (PC), which represents a first-order approximation to the "pure" component spectrum. This approximation is useful for deciding rationally which absorption peaks are most important in this analysis. In agreement with the results of PLS modeling, a general difference in spectral shape between the two data sets is evident (convex vs. concave across the VIS region), supporting seasonal variance in the mineral
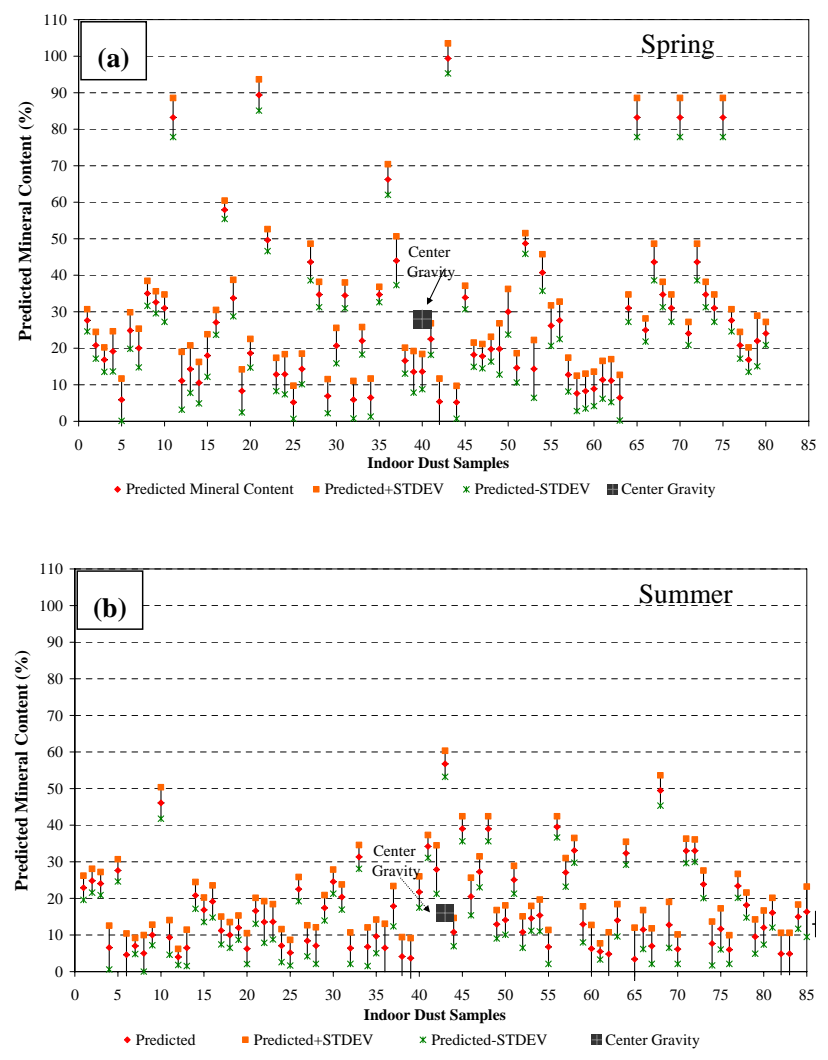

Fig. 5. Predicted mineral contents for spring (upper, a) and summer (lower, b) dust samples with corresponding standard deviations.

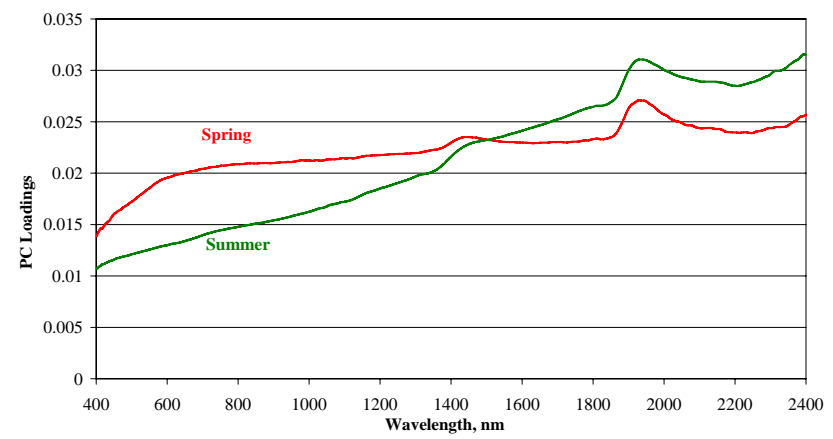

Fig. 6. First PC loading vector according to PCA analyses for each season.

content of samples. The second PC for both data sets (figure not shown) allows visualization across the SWIR spectral region (1100-2400 nm) of the scattering effect due to the assortment of dust particles present in the samples (Chudnovsky et al., 2007), and also confirms differences in spectral shape across VIS between seasonal dust samples. In spring, distinctive absorptions appear at $2220 \mathrm{~nm}, 2340 \mathrm{~nm}$, and $2360 \mathrm{~nm}$, which can be attributed to minerals such as clay and carbonates, respectively (Hunt, 1977). Absorbance 
Table 2. Assessed Mineral Content (in \%).

\begin{tabular}{lll}
\hline $\begin{array}{l}\text { Assessed Mineral Content } \\
\text { (Predicted in \%) }\end{array}$ & Spring & Summer \\
\cline { 2 - 3 } & Number of samples & Number of samples \\
\hline $0-15$ & 24 & 52 \\
$16-30$ & 27 & 24 \\
$31-46$ & 17 & 9 \\
$47-65$ & 5 & 3 \\
$66-80$ & 1 & 0 \\
$81-100$ & 6 & 0 \\
\hline Total & 80 samples & 88 samples \\
\hline Negative values (not con- & 10 samples & 47 samples \\
tained mineral content) & & \\
\hline Total Experiment & 90 samples & 135 samples \\
\hline
\end{tabular}

at $2200 \mathrm{~nm}$ is observed in samples from both seasons. The higher mineral content among summer samples is likely due to the Etesian winds and sea breeze causing sand from the beach to infiltrate indoors. In summary, the data reflects that the five major dust storms, which occurred during the spring data acquisition, influenced the composition of indoor dust, and resulted in a higher mineral content for spring indoor dust samples as compared with summer indoor dust samples.

\section{Summary and future applications}

Chudnovsky et al. (2007) developed a method based on near infrared reflectance spectroscopy (NIRS) in the 1250$2400 \mathrm{~nm}$ spectral range to examine quantitatively small amounts of sediment dust. They demonstrated that the construction of a reliable multivariate calibration model enables precise prediction of a particulate dust sample's gravimetric weight from its spectral data. In the present study we report that using similar methods it is possible also to assess quantitatively the mineral content of a dust sample from its spectral data. Specifically, spectra derived from artificial laboratory dust mixtures were used in combination with PLS regression analysis to generate predicted mineral contents for field dust samples based on their reflectance spectra.

The shape of the spectrum reflects strongly the chemistry of the settled dust sample and was used to characterize the seasonal dust loads. Both the spectral shapes and predicted mineral contents indicate that dust loads in the spring are different from those in the summer. During the spring season most samples exhibit a convex spectral shape across the VIS region indicative of higher mineral content, and a concave spectral shape indicative of higher anthropogenic content is seldom observed. The opposite was found in the summer season. These seasonal differences are explained by the se- vere dust events during the spring season, which do not occur during the summer. Dust load research carried out in Northern China and Africa indicates also that dust sediments can exhibit a high mineral content, likely due to iron oxides, hematite or goethite (Arimoto et al., 2002; Shen et al., 2006); in these studies large amounts of dust collected on bulk filters were analyzed using spectral and chemical methods.

The spectral method developed in this report can potentially be applied to measure quantitatively other components within settled dust, such as pollen, soil, asbestos, cement, and iron oxides. For these dust constituents, dust loads of any size have pathological significance, even if the dust never becomes airborne (Morawska and Salthammer, 2004). Although pollen and asbestos have unfortunate, wide reaching effects on human health, these materials have the advantage of possessing significant spectral fingerprints and therefore represent promising candidates for spectral study. Another potential application of the methods described here is qualitative mapping of the chemical components of settled particles; for this multivariate calibration analyses would need to be combined with reflectance spectroscopy. Importantly, the methods developed here potentially represent the basis for a system that provides comprehensive spectralspatial overviews of indoor environments in almost real time. Such a system would require imaging spectroscopy (IS) cameras that can determine quantitatively dust levels, and the data generated would be recorded and stored. Therefore the spectral-based technology described here has significant potential to bridge the gap between required and existing methods for rapid assessment of indoor dust distribution. 


\section{Conclusions}

It is demonstrated here that reflectance spectroscopy in conjunction with multivariate calibration analysis enables rapid and accurate assessment of settled dust composition, even when monitoring only small amounts of chemical material. The presented optical method is validated to be reliable and has many potential applications. Environmental researchers and policy makers can use the information generated by this method about the nature of dust loads to improve indoor conditions and to track dust contamination following environmental change.

Acknowledgement. This study was supported by the Israeli Science Foundation (ISF, grant no. 764/06). We thank all residents and individuals who agreed to participate in the field study experiments.

Edited by: P. Alpert, H. Saaroni, and E. Heifetz

Reviewed by: two anonymous referees

\section{References}

Adams, M.: Chemometrics in Analytical Spectroscopy, Cambridge, Royal Society of Chemistry, 1995.

Alpert, P., Abramski, R., and Neeman, B. U.: The prevailing summer synoptic system in Israel - subtropical high, not Persian trough, Isr. J. Earth Sci., 39, 93-102, 1990.

Alpert, P. and Ziv, B.: The Sharav Cyclone - Observation and some theoretical considerations, J. Geophys. Res., 94(D15), 18495 $18514,1989$.

Arimoto, R., Balsamb, W., and Schloesslina, C.: Visible spectroscopy of aerosol particles collected on filters: iron-oxide minerals, Atmos. Environ., 36, 89-96, 2002.

Chudnovsky, A., Ben-Dor, E., and Paz, E.: Using NIRS for rapid assessment of sediment dust in the indoor environment, JNIRS, 15(1), 59-70, 2007.

Chudnovsky, A. and Ben Dor, E.: Reflectance spectroscopy as a tool for settled dust monitoring in office environment, Int. J. Environ. Waste Manage., special issue on "Urban Air Pollution: Problems, Control Technologies and Management Practices", accepted, 2007.

Edwards, R., Yurkow, E., and Lioy, P.: Seasonal deposition of housedusts onto household surfaces, Sci. Total Environ., 224(13), 69-80, 1998.

Esbensen, K.: Multivariate Data Analyses, an Introduction to Multivariate Data Analyses and Experimental Design, 5th Edition, Alborg University, CAMO, 2002.

Fergusson, J. and Kim, N.: Trace elements in street and house dusts: sources and speciation, Sci. Total Environ., 100, 125-150, 1991.

Kalnay, E., Kanamitsu, M., Kistler, R., Collins, W., Deaven, D., Gandin, L., Iredell, M., Saha, S., White, G., Woollen, J., Zhu, Y., Chelliah, M., Ebisuzaki, W., Higgins, W., Janowiak, J., Mo, K. C., Ropelewski, C., Wang,J., Leetmaa, A., Reynolds, R., Jenne, R., and Joseph, D.: The NCEP/NCAR 40-Year Reanalysis Project, B. Am. Meteorol. Soc., 77, 437-471, 1996.
Kistler, R., Kalnay, E., Collins, W., Saha, S., White, G., Woollen, J., Chelliah, M., Ebisuzaki, W., Kanamitsu, M., Kousky, V., van den Dool, H., Jenne, R., and Fiorino, M.: The NCEP/NCAR 50year reanalysis: Monthly means CD-ROM and documentation, B. Am. Meteorol. Soc., 82, 247-267, 2001.

Lioy, P., Freeman, N., and Millette, J.: Dust: a metric for use in residential and building exposure assessment and source characterization, Environ. Health Perspect., 110, 969-983, 2002.

Lloyd, P. E. and Dicken, P.: Location in Space: A Theoretical Approach to Economic Geography, New York, Evanston, San Francisco, and London, Harper \& Row, pp. 186-93, 1972.

Maertens, R., Bailey, J., and White, P.: The mutagenic hazards of settled house dust: a review, Mutation Res., 567, 401-425, 2004.

Morawska, L. and Salthammer, T.: Fundamentals of Indoor Particles and Settled Dust, in: Indoor Environment: Airborne Particles and Settled Dust, edited by: Morawska, L. and Salthammer, T., Germany, WILEY-VCH, 1-46, 2004.

Hunt, G. R.: Spectral signatures of particulate minerals, in the visible and near-infrared, Geophys., 42, 501-513, 1977.

Ong, C. H., Cudahy, T. J., Caccetta, M. S., and Piggott, M. S.: Deriving quantitative dust measurements related to iron ore handling from airborne hyperspectral data, Mining Technology: IMM Transactions section A, 112(3), 158-163(6), 2003.

Riley, W. J., McKone, T. M., Lai, A. C. K., and Nazaroff, W. W.: Indoor particulate matter of outdoor origin: Importance of size-dependent removal mechanisms, Environ. Sci. Technol., 36, p. 1868, 2002.

Roberts, J. W., Budd, W. T., Ruby, M. G., Camann, D. E., Fortmann, R. C., Lewis, R. G., Wallace, L. A., and Spittler, T. M.: Human exposure to pollutants in the floor dust of homes and offices, J. Exposure Analysis \& Environ Epidemiology, Suppl. 1, 127-146, 1992.

Saaroni, H. and Ziv, B.: Summer rainfall in a Mediterranean climate - The case of Israel: climatological - dynamical analysis, Int. J. Climatol., 20, 191-209, 2000.

Shen, Z., Cao, J., Zhang, X., Arimoto, R., Ji, J., Balsam, W., Wang, Y., Zhang, R., and Li, X.: Spectroscopic analysis of iron-oxide minerals in aerosol particles from northern China, Sci. Total Environ., 367, 2-3, 899-907, 2006.

Shneider, T.: Sampling of Surface Dust in Buildings, in: Indoor Environment: Airborne Particles and Settled Dust, edited by: Morawska, L. and Salthammer, T., Germany, WILEY-VCH, pp. 82-104, 2004.

Vallack, H. and Shillito, D.: Suggested Guidelines for Deposited Ambient Dust, Atmos. Environ., 32(16), 2737-2744, 1998.

Ziv, B., Saaroni, H., and Alpert, P.: The factors governing the summer regime of the eastern Mediterranean, Int. J. Climatol., 24, 1859-1871, 2004. 